Article

\title{
The Extracellular Domain of Human High Affinity Copper Transporter (hNdCTR1), Synthesized by $E$. coli Cells, Chelates Silver and Copper Ions in Vivo
}

\author{
Tatiana P. Sankova 1,2, Iurii A. Orlov 1,2, Andrey N. Saveliev 1, Demid A. Kirilenko 2,3, Polina S. \\ Babich ${ }^{4}$, Pavel N. Brunkov ${ }^{2,3}$, and Ludmila V. Puchkova ${ }^{1,2, *}$ \\ 1 Department of Biophysics, Peter the Great St. Petersburg Polytechnic University, Politekhnicheskaya str., \\ 29, St.-Petersburg, 195251 Russia; sankova@yandex.ru (T.P.S.); orlov239@gmail.com (I.A.O.); \\ savelev_andrew@mail.ru (A.N.S.); puchkovalv@yandex.ru (L.V.P.) \\ 2 Department of Modern Functional Materials, ITMO University, Kronverksky av., 49, St.-Petersburg, \\ 197101, Russia; zumsisai@gmail.com (D.A.K.); brunkov1964@mail.ru (P.N.B.) \\ 3 Center of Nanoheterostructures Physics, Ioffe Institute, Politekhnicheskaya str., 26, St.-Petersburg, 194021, \\ Russia \\ 4 Department of Zoology, Herzen State Pedagogical University of Russia, Kazanskaya str., 6, St.-Petersburg, \\ 191186, Russia; babich.polina@gmail.com \\ * Correspondence: puchkovalv@yandex.ru; Tel.: +7-921-881-8470
}

\begin{abstract}
There is much interest in effective copper chelators to correct copper dyshomeostasis in neurodegenerative and oncological diseases. In this study, a recombinant fusion protein for expression in E. coli cells was constructed from glutathione-S-transferase (GST) and the N-terminal domain (ectodomain) of human high affinity copper transporter CTR1 (hNdCTR1), which has three metal-bound motifs. Several biological properties of the GST-hNdCTR1 fusion protein were assessed. It was demonstrated that in cells, the protein was prone to oligomerization, formed inclusion bodies and displayed no toxicity. Treatment of E. coli cells with copper and silver ions reduced cell viability in a dose- and time-dependent manner. Cells expressing GST-hNdCTR1 protein demonstrated resistance to the metal treatments. These cells accumulated silver ions and formed nanoparticles that contained $\mathrm{AgCl}$ and $\mathrm{Ag} 0$. In this bacterial population, filamentous bacteria with length about $10 \mu \mathrm{m}$ were often observed. The possibility for the fusion protein carrying extracellular metal binding motifs to integrate into the cell's copper metabolism and its chelating properties are discussed.
\end{abstract}

Keywords: CTR1 metal-binding extracellular domain cloning; copper/silver chelation; E. coli filamentous growth; secondary silver nanoparticles formation

\section{Introduction}

Copper is a structural and catalytic cofactor of vitally essential enzymes [1,2]. Also, it controls activity of ubiquitous and specific transcription factors (e.g., HIF1, p53, Sp1) [3-5], participates in cell signaling, cell cycle control, and apoptosis [6-11], and it is required for neovascularization [12]. At the same time, copper is a potentially toxic agent, so its ions can initiate Fenton type reactions and produce reactive oxygen species that provoke oxidative stress increasing the risk of development of severe cardiovascular, neurodegenerative and neoplastic diseases [13,14]. Furthermore, in patients with disorders associated with hepatic copper accumulation, zinc in the DNA-binding domain of the nuclear hormone receptors is replaced by copper; and as a result, the specific binding of hormone receptors to their cis-elements is disrupted [15]. In cells and extracellular spaces of multicellular organisms, copper is bound in coordination spheres of cuproenzymes [13], copper transporting [16] or depositing proteins [17]. It can be released when the structure of these proteins is damaged [18]. Therefore, copper chelators are considered as a promising therapeutic agent to scavenge of free copper ions in the extra- and intracellular spaces [11,19-22]. 
The central member of a safe copper transport into eukaryotic cells is the highly-conserved protein CTR1, which belongs to the family of high affinity $\mathrm{Cu}(\mathrm{I})$ transporters [23]. CTR1 is localized in the cell membrane and functions as a homotrimer of $35 \mathrm{kDa}$ glycoprotein subunits. The subunit contains a N-terminal extracellular (ecto)domain (NdCTR1), a transmembrane domain including 3

-helical motifs, and a short cytosolic C-terminal domain with a copper binding $\mathrm{HCH}$-motif. The NdCTR1 is $\mathrm{N}$ - and O-glycosylated and contains 66 amino acid residues (in humans), which form a set of three unique metal-binding motifs: His/Met-, His-, and Met-enriched (Swiss-Prot: Q8K211.1). According to the concept of hard and soft acids and bases (Pearson's HSAB principle) they have different presumptive affinity for $\mathrm{Cu}(\mathrm{II})$ and $\mathrm{Cu}(\mathrm{I})$ [24]. Motifs 1 and 2 are presumably more affine to $\mathrm{Cu}(\mathrm{II})$, while motif 3 should be more affine to $\mathrm{Cu}(\mathrm{I})$ [25]. CTR1 was shown to bind abiogenic silver ions [26] and cisplatin (a widely used antitumor drug) [27] to transport them into the cells. Ag(I) is isoelectronic to $\mathrm{Cu}(\mathrm{I})$ so it is efficiently bound by $\mathrm{Cu}(\mathrm{I})$ transporters and carriers; however, it cannot be oxidized in aqueous media, and when included instead of copper to cuproenzymes, it disrupts their structure and catalytic activity [28]. This may be a basis for the use of silver to retard the growth of tumors that require increased amounts of copper [29,30]. A mechanism for transferring cisplatin through CTR1 is not fully understood.

The central position of CTR1 as the major pathway for cellular copper uptake in the intestinal epithelium, hepatic and non-hepatic tissue, and particularly tumor cells, as well as its competence to transfer silver and cisplatin, attract considerable attention to the properties of its $\mathrm{N}$-terminal domain. The kinetics of copper, silver and cisplatin binding to metal-binding motifs from NdCTR1 has been studied. Their role as well as the importance of single amino acid residues for copper and cisplatin transport has been evaluated [31-33]. However, currently there are no data on NdCTR1 properties as chelator for copper, silver or cisplatin in conditions that model the situation in vivo.

In this work, the ectodomain of human CTR1 (hNdCTR1) was cloned into an expression vector in E. coli cells, and the influence of recombinant protein on the sensitivity of E. coli cells to silver and copper ions was investigated. The realization that NdCTR1 can chelate copper has prompted the development of copper-specific chelator.

\section{Results}

\subsection{Cloning of hCTR1 ectodomain}

The DNA fragment, containing $198 \mathrm{bp}$ and corresponding to the full-sized hNdCTR1 was obtained by PCR with reverse transcription of total RNA fraction of HepG2 cells and cloned in pGEX$4 \mathrm{~T}-1$ vector as described in the Methods. The correctness of the cloned NdCTR1 inset was verified by direct sequencing (Figure 1A). The growth rates of E. coli BL21(DE3) transformed with pGEX-4T-1 or pNdCTR1 cells before and after incubation with IPTG were the same as the growth rate of the nontransformed strain (Figure 1B). IPTG-induced E. coli cells bearing the parent pGEX-4T-1 plasmid synthesized a 27.9-kDa polypeptide corresponding to GST (Figure 1C). The BL21 (DE3)/pNdCTR1 E. coli cells synthesized a 34.4-kDa polypeptide, and its molecular weight corresponded well to the calculated weight of the fusion protein, which included both GST and 66 amino acid residues of hNdCTR1 (Figure 1C). The maximum production of the fusion protein was observed at 3.5 hours after the induction with $0.5 \mathrm{mM}$ IPTG (Figure 1D). The fusion protein contained a region that was recognized by anti-CTR1 antibodies (Figure 1E). Thus, the presented data demonstrate successful expression of the cloned CTR1 ectodomain. After cell disruption, the major part of recombinant protein was found in the fraction known as inclusion bodies, which could not be solubilized under mild conditions of $2 \mathrm{M}$ urea and $1 \mathrm{mM} \beta$-mercaptoethanol (Figure $1 \mathrm{~F}$ ). In the cells transformed with pGEX-4T-1 plasmid, GST protein after IPTG induction was found in cytosol (major part) and in pellet (minor fraction). So, fusion protein demonstrated a higher propensity to form the inclusion bodies (Figure 1G). 
A

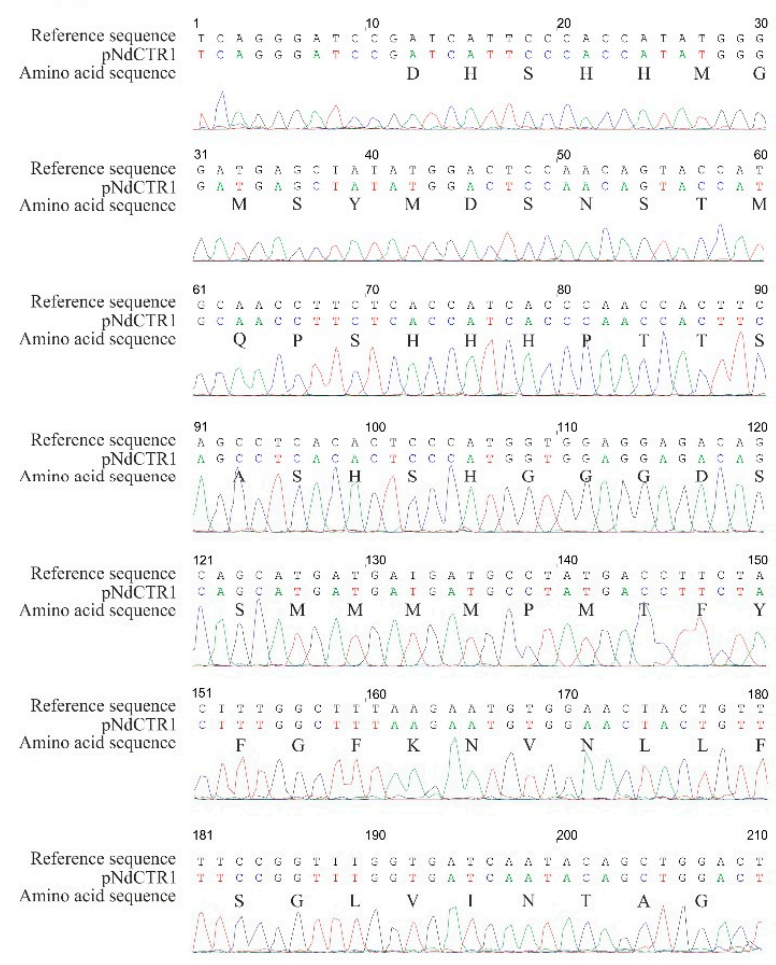

B

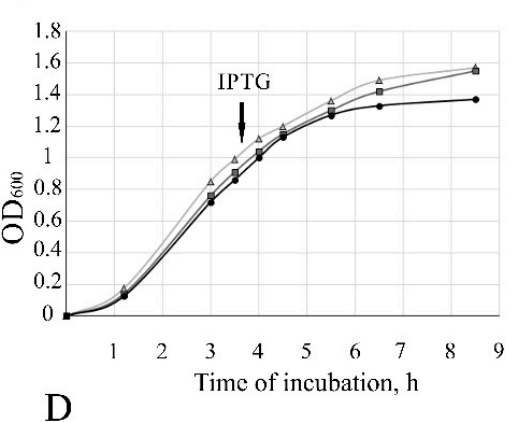

$\mathrm{C}$

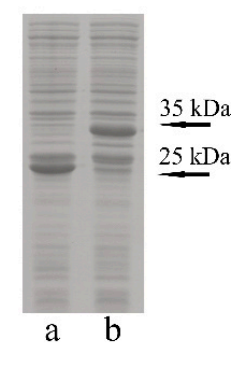

$\frac{35 \mathrm{kDa}}{25 \mathrm{kDa}}$

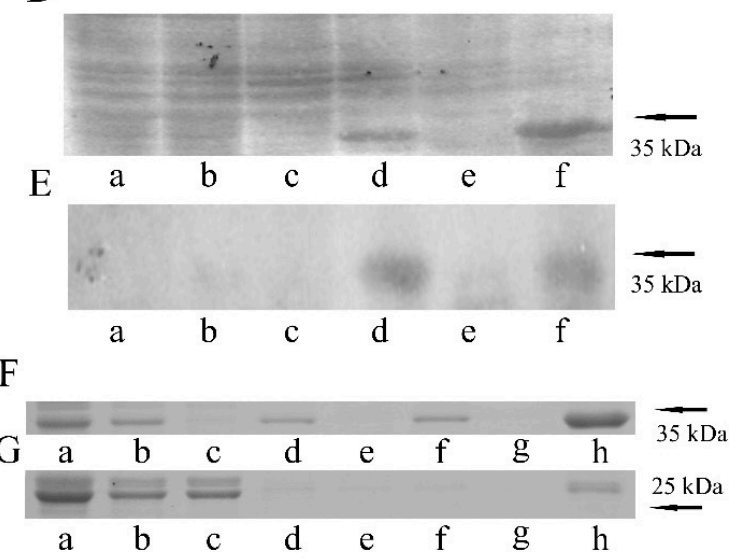

Figure 1. Cloning of hNdCTR1 and analysis of recombinant fusion protein. (A) The correspondence of the cloned nucleotide sequence to the region of the human CTR1 gene. (B) The growth rate of the control E. coli strain and strains transformed with plasmids expressing either GST or GST-hNdCTR1. Cycles - E. coli BL21(DE3); triangles - E. coli BL21(DE3)/pGEX-4T-1; squares - E. coli BL21(DE3)/pNdCTR1. (C) PAG-SDS electrophoresis of crude cellular extracts from E. coli BL21(DE3)/pGEX-4T-1 (lane a) and E. coli BL21(DE3)/pNdCTR1 (lane b) after incubation with IPTG for 3.5 hours. (D) PAG-SDS electrophoresis and (E) immunoblotting with antibodies to CTR1 of crude cellular extracts from E. coli BL21(DE3)/pNdCTR1 after incubation for 0, 1.5, and 3.5 hours. Lanes a, $\mathrm{b}, \mathrm{c}$ : total protein extract of non-induced culture; lanes $\mathrm{d}, \mathrm{e}, \mathrm{f}$ : total protein extract of IPTG induced culture. (F) and (G) PAG-SDS electrophoretic analysis of subcellular fractions from E. coli cells transformed with pNdCTR1 and pGEX-4T-1, respectively: cell crude extract (a), cell lysate after ultrasound treatment (b), soluble fraction of lysate obtained by centrifugation for $15 \mathrm{~min}$ at $16000 \mathrm{~g}$ (c). Insoluble fraction of pellet was 3 times treated with solution containing 1\% Triton X-100, $5 \mathrm{mM}$ DTT and $2 \mathrm{M}$ urea. After each treatment, soluble and insoluble fractions were separated by centrifugation for $15 \mathrm{~min}$ at $16000 \mathrm{~g}$. Consecutive pellets: $\mathrm{d}, \mathrm{f}, \mathrm{h}$, and corresponding to them soluble fractions: e, g. Arrows show molecular weights.

\section{2. hNdCTR1 polypeptide rescues E. coli cells from the toxic action of copper and silver ions}

Sensitivity of $E$. coli cells to toxic effect of copper and silver ions was evaluated by the conventional method of colony-forming unit (CFU) determination. The experiments were performed in IPTG-induced BL21(DE3)/pGEX-4T-1 or BL21(DE3)/pNdCTR1 strains. The cells were treated with copper sulfate or silver nitrate as described in the Methods. The results indicated that copper ions reduced the number of $\mathrm{CFU}$ in the reference strain more efficiently than in the strain producing recombinant hNdCTR1 (Figure 2). The effect depended on copper concentration (Figure 2A) and time of incubation (Figure $2 \mathrm{~B}$ and $\mathrm{C}$ ). 
A

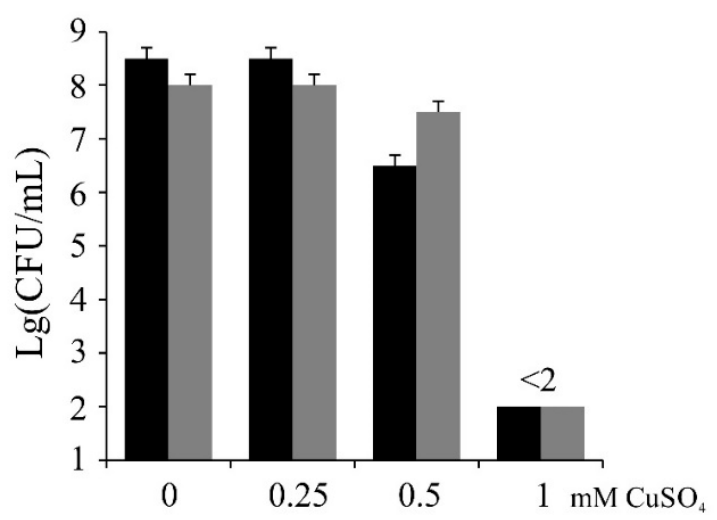

B
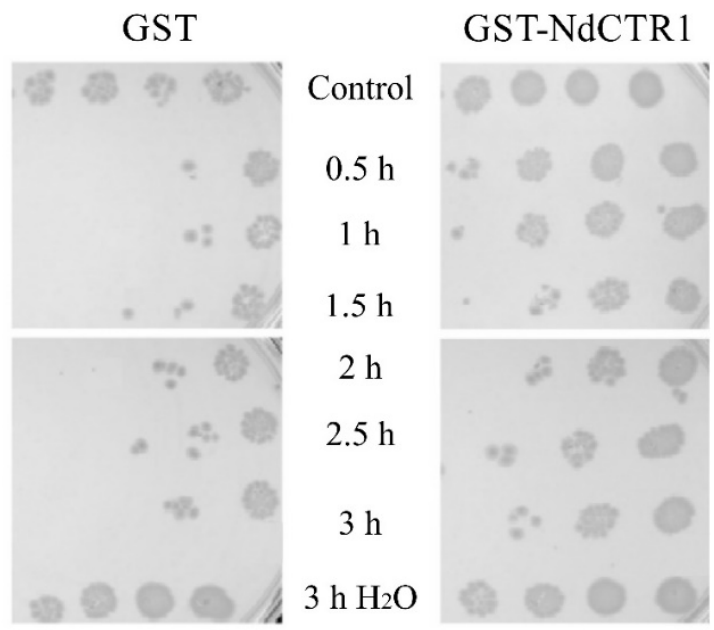

$\mathrm{C}$

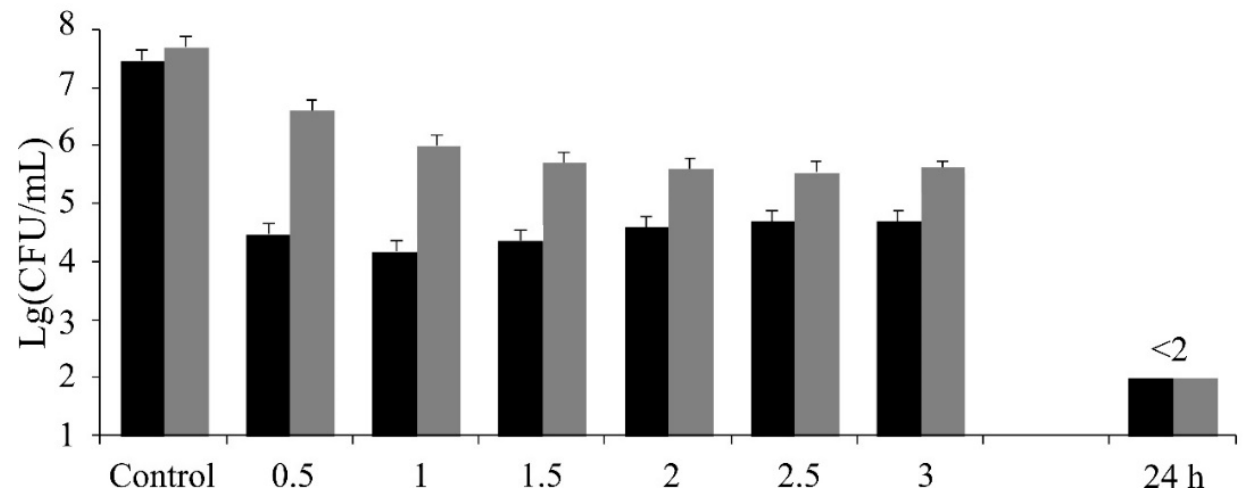

Figure 2. (A) Effect of copper ions concentration on E. coli BL21(DE3)/pGEX-4T-1 (black bars) and E. coli BL21(DE3)/pNdCTR1 (grey bars) after 24 hours of treatment. Abscissa: $\mathrm{CuSO}_{4}$ concentration, mM; ordinate: CFU, lg. (B) Effect of time on survival of E. coli BL21(DE3)/pGEX-4T-1 and E. coli BL21(DE3)/pNdCTR1 treated with $0.25 \mathrm{mM}$ copper ions (protocol of the experiment). (C) Bar graph corresponding to the (B) experiment repeated 3 times. Black bars - E. coli BL21(DE3)/pGEX-4T-1; grey bars - E. coli BL21(DE3)/pNdCTR1.

In the same manner hNdCTR1 rescued E. coli cells from toxic effect of silver ions (Figure 3A-D). Two features of the silver ions action on the survival of bacteria attract attention. First, the effect is biphasic: the survival of cells dropped sharply in 5 minutes after the beginning of treatment, then it raised and decreased again at longer periods of treatment. The rescue effect of $\mathrm{hNdCTR} 1$ manifested itself at long treatment times (Figure 3D). Second, the rescue effect of hNdCTR1 was associated with 
silver accumulation. So, the total concentration of silver was 2 times higher in cells producing hNdCTR1-GST than in the cells expressing parent GST (Figure 3E), and the viability of the former cells was higher (Figure 3B and D). The ability of the fusion protein to defend bacteria from cisplatin was also evaluated. The cells synthesizing fusion protein showed higher survival in the presence of the drug, but only 2-fold (data not shown).

A

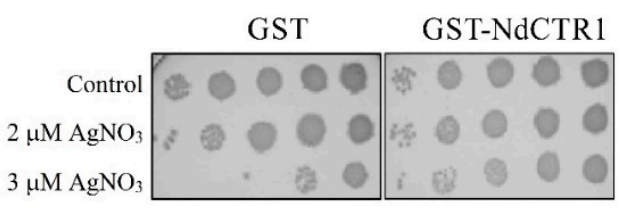

B

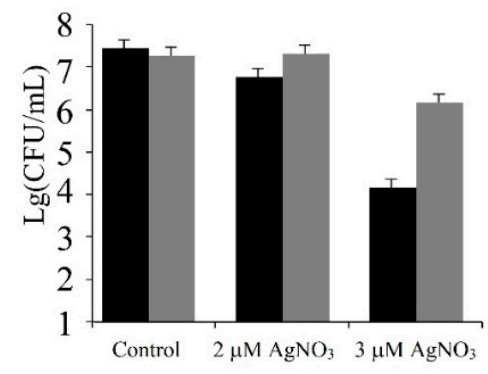

$\mathrm{D}$

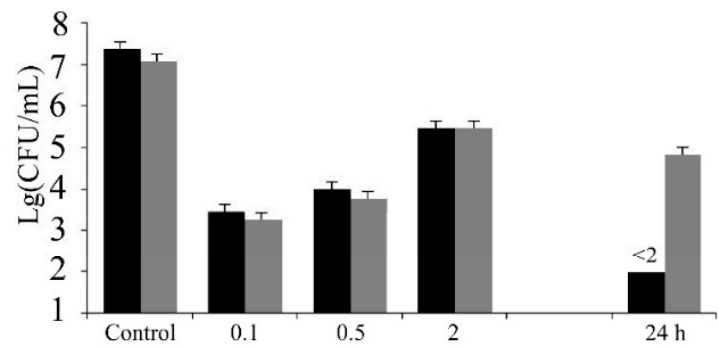

$\mathrm{E}$

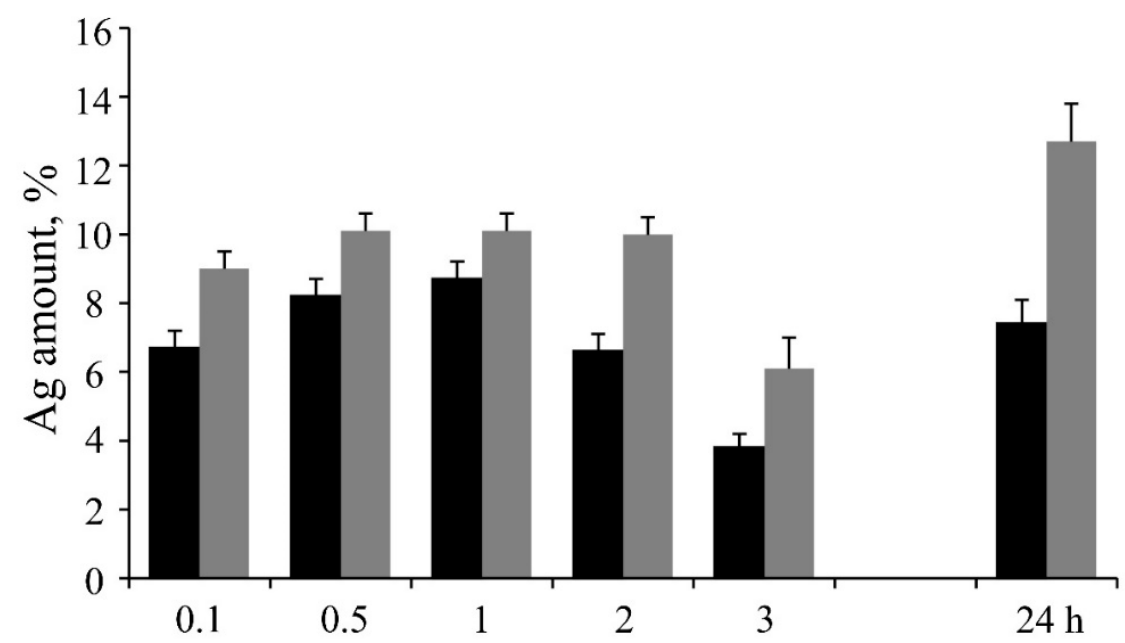

Figure 3. (A) Effect of silver ions on E. coli Bl21(DE3)/pGEX-4T-1 and BL21(DE3)/pNdCTR1 after 24 hours of treatment (protocol of the experiment). (B) Bar graph corresponding to the (A) experiments repeated 3 times. Black bars: E. coli B121(DE3)/pGEX-4T-1; grey bars: BL21(DE3)/pNdCTR1. Abscissa: $\mathrm{AgNO}_{3}$ concentration, $\mu \mathrm{M}$; ordinate: $\mathrm{CFU}$, lg. (C) Effect of time on survival of $E$. coli BL21(DE3)/pGEX4T-1 and E. coli BL21(DE3)/pNdCTR1 treated with $3.5 \mu \mathrm{M} \mathrm{AgNO}$ (protocol of the experiment). (D) Bar graph corresponding to the (C) experiment treated 3 times. Black bars: E. coli B121(DE3)/pGEX4T-1; grey bars: BL21(DE3)/pNdCTR1. Abscissa: time of treatment, h; ordinate: CFU, lg. (E) Dynamic of Ag accumulation by E. coli BL21(DE3)/pGEX-4T-1 (black bars) and E. coli BL21(DE3)/pNdCTR1 (grey bars) during incubation in $3.5 \mu \mathrm{M} \mathrm{AgNO}_{3}$. Abscissa: time, h; ordinate: $\mathrm{CFU}, \mathrm{lg}$. 


\section{3. $h N d C T R 1$ chelates silver ions}

To investigate the ability of hNdCTR1 to bind metal ions we used silver ions as they are considerably easier to track, because they are absent in the cells under normal conditions and transported into the cell and excreted via the same pathways as copper. According to the gelfiltration, in E. coli cells expressing the parent pGEX-4T-1 plasmid, GST functional homodimers were observed (Figure 4A).

A

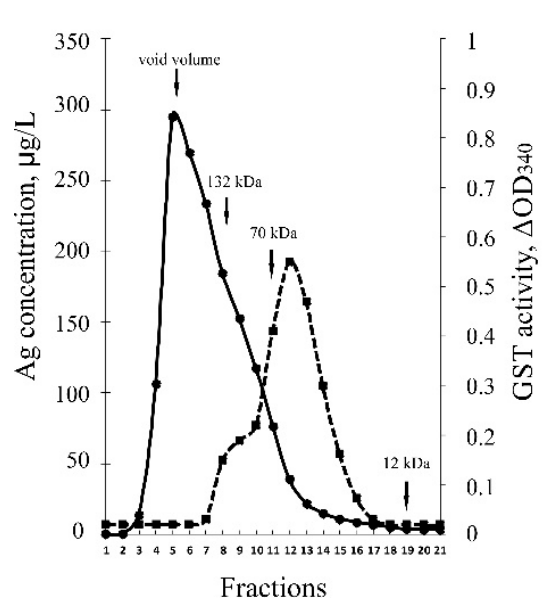

B

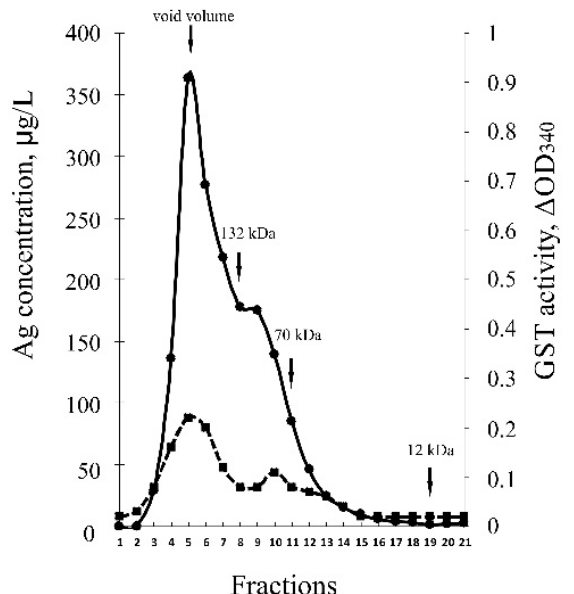

Figure 4. Distribution of silver and GST enzymatic activity in cytoplasm of $E$. coli cells synthetizing GST (A) and GST-hNdCTR1 (B). Solid line - silver concentration; dotted line-GST enzymatic activity. The details of chromatographic analysis are described in Methods (section 2.6). The arrows show elution rate of marker proteins: $132 \mathrm{kDa}$ - human ceruloplasmin, $70 \mathrm{kDa}$ - bovine serum albumin, 12 $\mathrm{kDa}$ - horse cytochrome C. (C) Amount of silver precipitated by antibodies to CTR1. Dark bar: E. coli BL21(DE3)/pGEX-4T-1; shaded bar - E. coli BL21(DE3)/pNdCTR1.

In the cells synthesizing the fusion protein (Figure 4B), GST activity was also present in fractions, corresponding to GST-hNdCTR1 homodimers $(\sim 70 \mathrm{kDa})$. However, the major part of GST activity was observed in the molecular mass region corresponding to multimers of the fusion protein (more than $110 \mathrm{kDa}$ ). The ability of full-sized hCTR1 subunits to form oligomers was described previously, and it was attributed to the properties of the transmembrane domain [34]. The data show that the polypeptide moiety of ectodomain may have its own role in CTR1 oligomerization. It is possible that oligomerization may be a result of the absence of the carbohydrate chains. Also, it cannot be excluded that hydrophobic region located behind the Met-rich motif on the C-terminal of the NdCTR1 (see Figure 1A) is responsible for the oligomerization.

The GST activity of the fusion protein was approximately 4 times lower than of the parent GST. Most likely, the tendency of the fusion protein to form oligomers partially blocked the access of the substrate to GST active center. Silver atoms were found to be associated with both homodimers and multimers of the fusion protein, but not with GST dimers (Figure 4B). Antibodies to CTR1 precipitated complexes containing silver ions from cellular lysate. The silver content was 3-4 times higher than in the non-specific precipitate (Figure 4B).

\subsection{Silver ions induced morphological changes in E. coli cells, which expressed fusion protein}

The TEM analysis revealed no morphological changes in the bacterial cells synthesizing GST (Figure 5A) or GST-hNdCTR1 (Figure5B). 
A

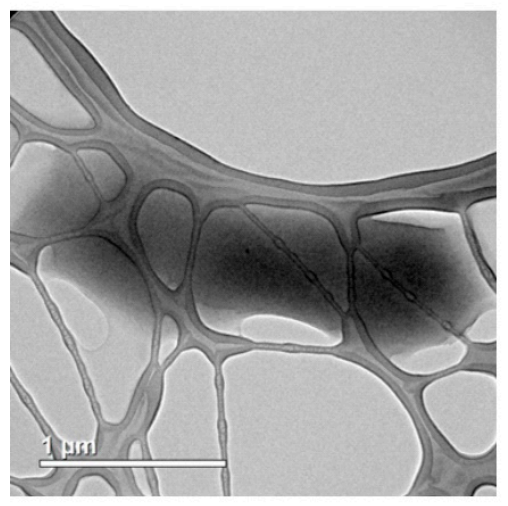

$\mathrm{B}$

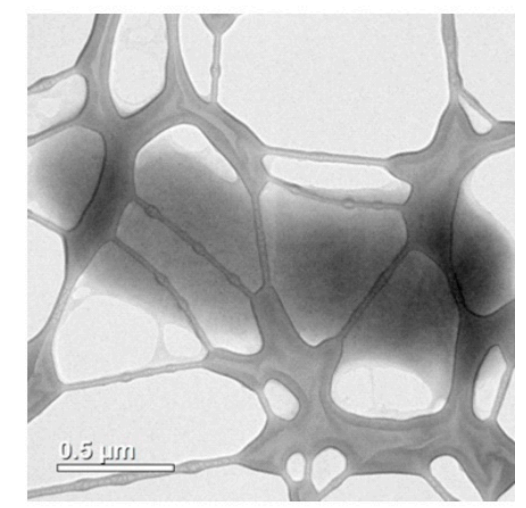

$\mathrm{C}$

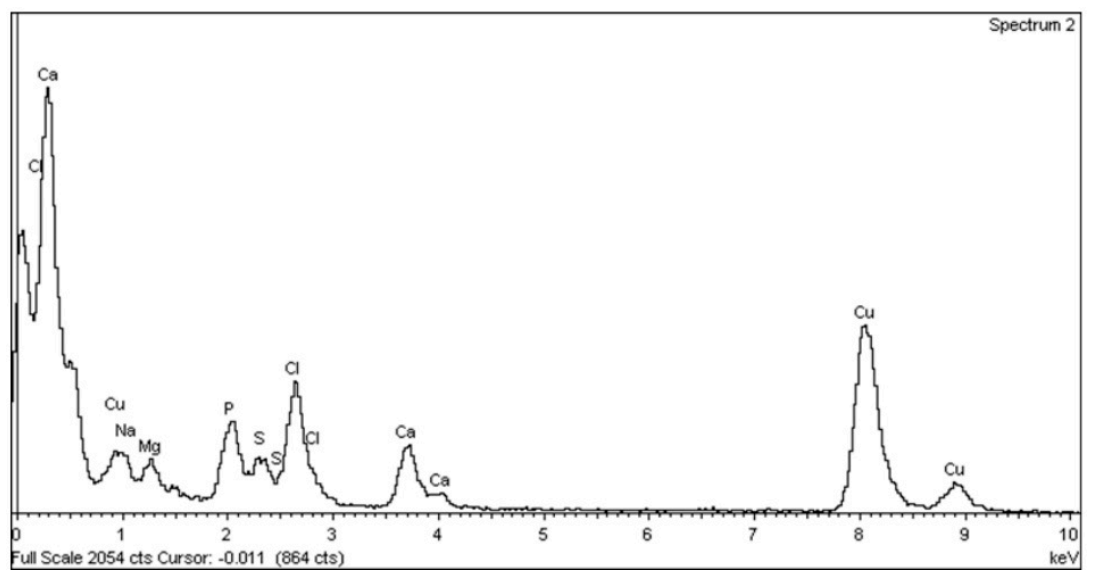

Figure 5. TEM image of E. coli cells expressing GST (A) or a fusion (GST-hNdCTR1) proteins (B), which were not treated with silver nitrate. (C) EDS analysis of cells expressing the fusion protein.

After $\mathrm{AgNO}_{3}$-treatment, most of the cells synthesizing GST had the unchanged morphology (Figure 6A), and contained inclusions of silver chloride (Figure 6B). In a single case, silver nanoparticles (SNP) were observed (Figure 6C and D). 
A

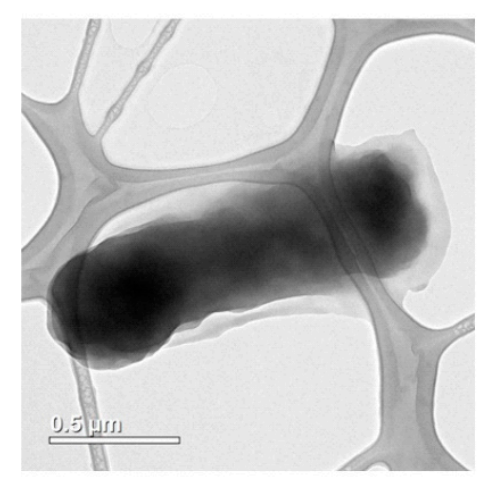

C

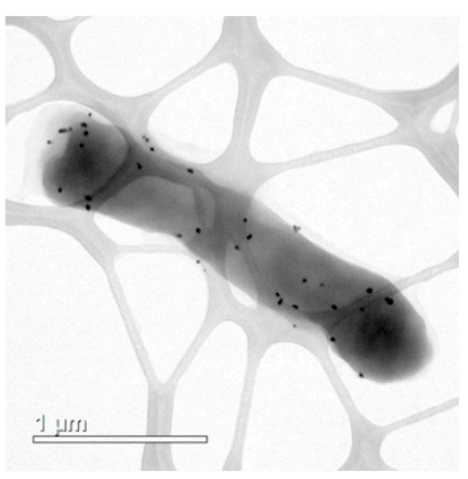

B

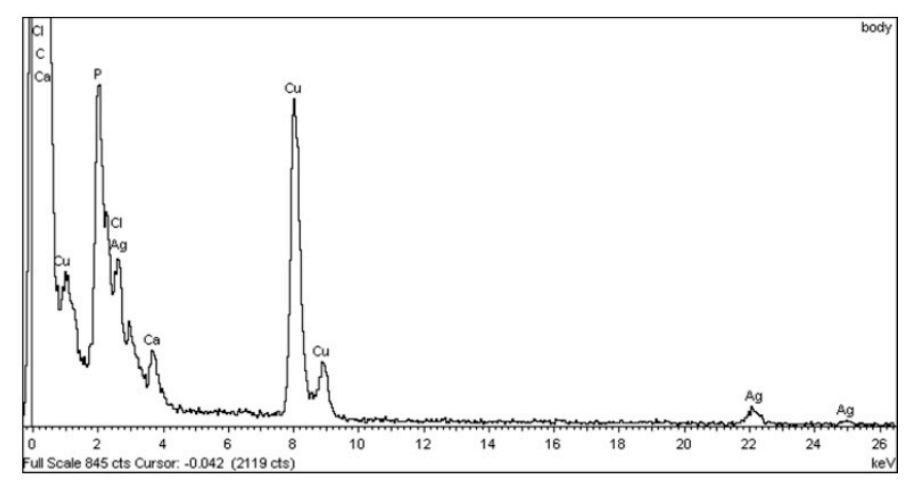

D

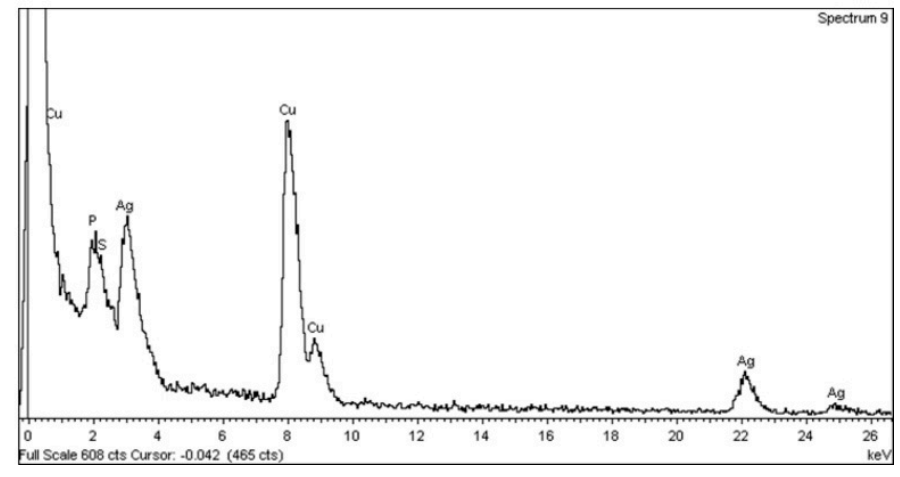

Figure 6. (A) TEM images of typical E. coli cell expressing GST treated with silver nitrate and (B) characteristic EDS spectrum of these bacteria. (C) A cell of the same strain, with formed SNP and (D) the characteristic EDS spectrum for cells expressing GST and forming SNP-like corpuscles.

In the population of the cells synthesizing the fusion protein GST-hNdCTR1, the formation of $\mathrm{AgCl}$ aggregates were found in some cases (Figure 7A and D), but the SNP were observed in most of the cells (Figure 7B). 
A

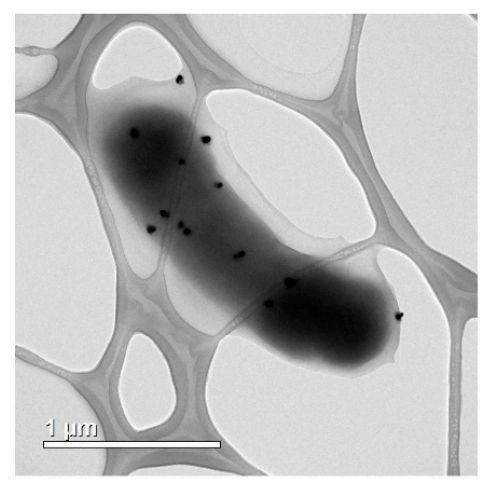

$\mathrm{D}$

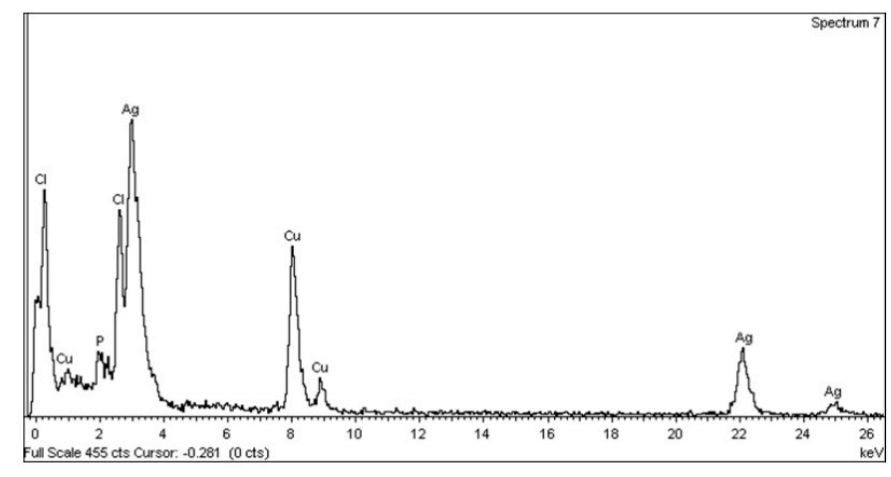

$\mathrm{C}$

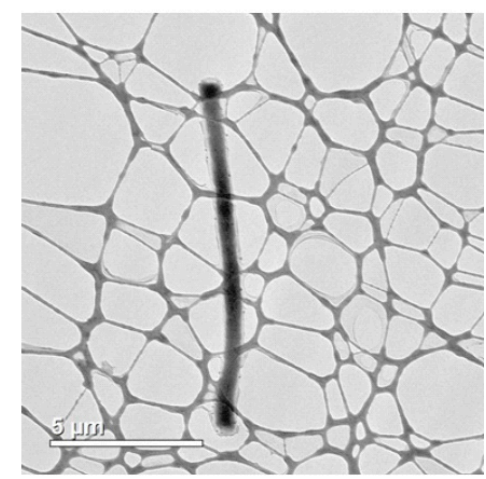

$\mathrm{E}$

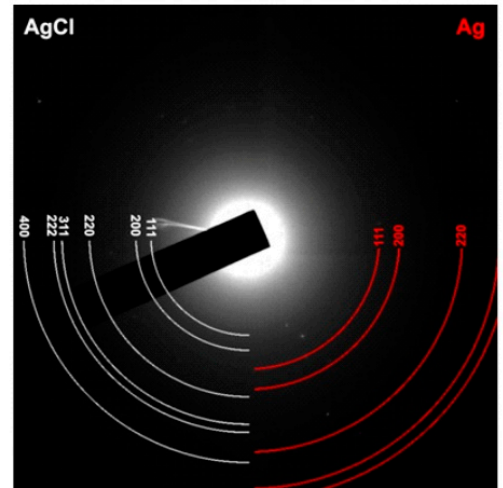

Figure 7. Typical TEM image of silver nitrate-treated E. coli cells expressing the fusion (GSThNdCTR1) protein with $\mathrm{AgCl}$ aggregates (A) and with formed SNP (B). (C) Filamentous bacterium. (D) Characteristic EDS spectrum of the formed SNP. (E) Electron diffraction analysis of the formed SNP.

In this cell population, filamentous cells contained SNP with the length exceeding $10 \mu \mathrm{m}$ were predominant (Figure 7C). Electron diffraction analysis showed that the resulting nanoparticles contained both silver chloride and metallic silver (Figure 7E).

\section{Discussion}

This paper presents data on the specific properties of the extracellular hNdCTR1 inside the bacterial cells. The full-sized hNdCTR1 was cloned by conventional approaches in E. coli cells as a part of the GST-fusion protein. This domain's identity to the human NdCTR1 was confirmed by direct sequencing of the insertion and by immunological assays (Figure 1). The protein was progressively synthesized after induction with IPTG and mostly accumulated in inclusion bodies, although some part of the protein was present in the soluble fraction (Figure 1 and 4). Expression of the heterogenous protein did not affect the bacterial growth rate (Figure 1B) and cell's morphology (Figure 5B), however, it saved the bacteria from the toxic effects of copper and silver ions in a dose- and timedependent manner (Figure 2 and 3). Rescue of bacteria synthesizing protein with hNdCTR1 from silver ions occurred in parallel with silver accumulation (Figure 3F).

After treatment of cells with silver ions, the biphasic pattern of the bacterial viability/time relationship was observed (Figure 3D). E. coli has three homeostatic systems that sustain low cytoplasmic copper/silver levels. First, CopA is an ATPase that pumps out copper from the cytoplasm to periplasmic space. Second, $\mathrm{CueO}$ is an oxidase that is considered to oxidize periplasmic $\mathrm{Cu}(\mathrm{I})$ to $\mathrm{Cu}$ (II) thus preventing copper from entering the cytoplasm. CopA and $\mathrm{CueO}$ are both induced when the cell is exposed to high copper concentrations. When copper concentrations become critical, the third system, Cus, which pumps out copper from the periplasm to extracellular space, is activated [35]. The systems can be used by bacteria to reduce silver toxicity because many properties of silver 
and copper ions are similar. In parallel, silver is chelated with high affinity by the recombinant $\mathrm{hNdCTR} 1$ and thus detoxified by sequestration from the copper transport routes. The probability of direct hNdCTR1 involvement in bacterial copper transport is very low, as cellular Cu-chaperones contain cysteine-based metal-binding motifs (CXXC), while NdCTR1 extracellular motifs are completely unrelated to them and do not contain cysteine residues.

The gel-filtration data (Figure 4A), CTR1 immunoprecipitation studies (Figure 4C) and electron diffraction analysis (Figure 7) are in good agreement with each other and demonstrate that silver is chelated by NdCTR1, resulting in the decrease of toxic effects (Figure 3). The survival is possibly enhanced by the activation of the stress response, which is manifested by filamentous growth [36] and the appearance of cells longer than $10 \mu \mathrm{m}$ (Figure 7C). The presented data firmly show that NdCTR1 chelates the excess of copper and silver ions inside the cells. The cell growth is not retarded, so it may be suggested that NdCTR1 does not affect normal cellular copper transport and does not extract copper from the bacterial cuproenzymes.

The ability of hNdCTR1 to chelate metals may be used for practical purposes. Copper dyshomeostasis is a ubiquitous feature of various neurodegenerative, oncology and cardiovascular diseases, so biogenic chelating agents can be considered as promising candidates for the development of new therapeutic agents [37,38]. NdCTR1 has many favorable properties compared to the chelators used in clinics: (a) it is an ectodomain of a natural human protein that is highly conserved in mammals, it should not display much in-species variability, and thus the induction of an immune response would be unlikely; (b) NdCTR1 is a multifunctional chelator (it can bind $\mathrm{Cu}(\mathrm{I})$ and $\mathrm{Cu}(\mathrm{II})$, $\mathrm{Ag}(\mathrm{I})$, and a series of platinum compounds); (c) it does not contain cysteine residues, meaning that it is not prone to oxidation to disulfides in the extracellular space, where no glutathione reducing system is available; therefore, apo-NdCTR1 can bind copper in the bloodstream and block its transport to tumors; (d) NdCTR1 does not extract copper from cuproenzymes, as copper chelators do [39].

In our work, we observed a conversion of silver ions to SNP (Figure 7). Recently, in vivo study in rats showed that ionic silver after single intravenous injection de novo formed secondary SNP, and the presence of such particles was proven by electron microscopy. However, silver ions were not bioavailable after oral ingestion [40]. At the same time, chronic diet with ionic silver induced formation of $\mathrm{Ag} 0$-inclusion in rats [28]. It is possible that $\mathrm{Ag}+\rightarrow \mathrm{Ag} 0$ conversion is a common protective mechanism in prokaryotes and eukaryotes against toxic effect of silver ions.

In summary, recombinant hNdCTR1 exhibited a specific chelating ability and was non-toxic. Therefore, it can be considered as a prospectively new therapeutic agent for different disorders that are linked to copper dyshomeostasis.

\section{Materials and Methods}

\subsection{E. coli strain and growth conditions}

The study was performed on E. coli cells of strain BL21 (DE3) (Stratagene) with the genotype E. coli B F- dcm ompT hsdS(rB- mB-) gal $\lambda$ (DE3). The cells were grown aerobically in liquid or agar nutrient medium based on bovine serum hydrolysate (Samson-Med, St. Petersburg, RU) at $37^{\circ} \mathrm{C}$. Antibiotic (ampicillin, Sigma) was used at the concentration $100 \mathrm{mg} / \mathrm{L}$.

\subsection{Cloning of N-terminal extracellular domain of $h$ CTR1}

The total RNA fraction was extracted from cultured HepG2 cells and used as a template for cDNA synthesis. A $198 \mathrm{bp}$ fragment of the SLC31A1 gene, corresponding to hNdCTR1, was amplified by PCR from the CDNA, using forward and reverse primers (Synthol, Moscow, RU): 5'cagggatccgatcattcccaccatatggggatg3' and 5'cagctcgagtccagctgtattgatcacca3'. The purified fragment (GeneJET PCR Purification Kit, Thermo Scientific) was then digested with the restriction enzymes BamH I and Xho I (New England Biolabs) and cloned into glutathione-S-transferase (GST) gene fusion plasmid vector pGEX-4T-1 (Amersham Biosciences, UK); the resulting plasmid was named pNdCTR1. E. coli strain BL21 (DE3)/pNdCTR1 was obtained by chemical transformation 
(TransformAid ${ }^{\mathrm{TM}}$, Thermo Scientific) of the bacteria. Plasmids were isolated using the alkaline method with GeneJET Plasmid Miniprep Kit (Thermo Scientific). Correctness of the DNA insertion was verified by restriction analysis and direct sequencing. Sequencing was carried out in a MegaBACE 1000 automated sequencer (Molecular Dynamics, United States) using a BigDye terminator v1.1 cycle sequencing kit (Applied Biosystems, UK). Fusion protein synthesis was induced by isopropyl- $\beta$-D-thiogalactoside (IPTG, Sigma). The optimum of IPTG concentration (0.5 mM) and induction time ( 3.5 hours) were determined basing on the amount of the target protein in the crude cell extract as determined by PAGE analysis. The protein bands were visualized by Coomassie G250. A commercial mix of proteins with molecular mass from 14 to $200 \mathrm{kDa}$ (Termo Scientific) was used as markers.

\subsection{Polyacrylamide gel electrophoresis, immunoblotting, and immunoprecipitation}

SDS-PAGE, protein transfer to nitrocellulose membrane (Amersham, UK) and visualization of immunoreactive products were carried out as described earlier [28]. To identify the recombinant protein, antibodies to CTR1 were used. The antibodies were obtained to a chemically synthesized 15mer peptide corresponding to the second metal-binding domain of hNdCTR1 (P15: 17TMQPSHHHPTTSASH31). The synthesized peptide was conjugated with hemocyanin isolated from red king crab (Paralithodes camtschaticus), and the complex was used for immunization of the rabbits. To test the specificity of the obtained antibodies, conjugates of p15 with succinylated bovine serum albumin (BSA) were applied [41]. The antibodies to P15/hemocyanin interacted with modified BSA/P15 and P15 displaced them from the immunocomplex; also, they detected the polypeptide corresponding to mono- and trimer of CTR1 on the plasma membrane of murine hepatocytes.

Immunoprecipitation was performed in aliquots of the cell lysate; protein concentration in the samples was equalized by OD280. The antiserum $(600 \mu \mathrm{L})$ to CTR1 was added to the same volume of the cell lysate and incubated overnight under continuous mixing at $4 \quad \mathrm{C}$. Next, $30 \mu \mathrm{L}$ of goat antirabbit IgG (Abcam) were added to the mixture and incubated for 4 hours at room temperature. The precipitate was collected by centrifugation and dissolved in pure nitric acid. Silver concentration was measured in both the lysate $(100 \%)$ and the immunoprecipitate, the quantity (\%) of silver bound to hNdCTR1 was calculated.

\subsection{Treatment of cells with $\mathrm{CuSO} 4$ or AgNO3}

E. coli cells were cultured overnight (E. coli strain expressing the GST-NdCTR1 fusion protein or the parent GST protein), washed with water and diluted 1:20 in a solution containing CuSO4 or AgNO3 in various concentrations. Control cell samples were incubated in water. After the treatment, the cells were titrated by 10 -fold dilution method to assess cell survival by colony forming ability on agar plates. Colonies were counted after $24 \mathrm{~h}$ incubation at $37^{\circ} \mathrm{C}$.

\subsection{Disruption and fractionation of bacterial cells}

Cells were washed with water, resuspended and treated with lysozyme ( $1 \mathrm{mg} / \mathrm{ml}$, Serva) for 30 min at room temperature. Next, the cells were disrupted by ultrasound (UZDN-2T, $44 \mathrm{kHz}$, twelve $30 \mathrm{sec}$ cycles with $60 \mathrm{sec}$ intervals for cooling) in an ice bath. The soluble cytoplasmic fraction was separated by centrifugation (15000 $\mathrm{g}, 10 \mathrm{~min}, 4 \mathrm{C})$ and used for chromatographic and immunoprecipitation studies. The samples were equalized by OD280.

\subsection{Gel-filtration chromatography}

Bacterial cytosol samples were fractioned by gel-filtration on a Sephacryl S-200 column equilibrated with $20 \mathrm{mM}$ Tris- $\mathrm{HCl}, 100 \mathrm{mM} \mathrm{NaCl}$ buffer, $\mathrm{pH}$ 7.6. Detection of the biological material was carried out by spectrophotometry at $280 \mathrm{~nm}$. The void volume of the column was estimated using blue dextran (Sigma). The fractions $(\sim 1.5 \mathrm{~mL})$ were collected; GST activity and silver concentration were measured in each fraction. The column was calibrated with blue dextran, electrophoretically 
pure human ceruloplasmin, $132 \mathrm{kDa}(\mathrm{A} 610 / 280=0.054)$, isolated by 2-stage chromatography [42], $\mathrm{BSA}, 70 \mathrm{kDa}$ (Sigma), and horse cytochrome C, $13 \mathrm{kDa}$ (Serva).

\subsection{GST activity determination}

GST activity was measured with glutathione (Serva) and 1-chloro-2,4-dinitrobenzene (Sigma) according to the Sigma protocol (https://www.sigmaaldrich.com/content/dam/sigmaaldrich/docs/Sigma/Bulletin/cs0410bul.pdf). The change in absorbance at $340 \mathrm{~nm}$ was recorded automatically at a room temperature and the GST activity was expressed in terms of change in absorbance per 1 minute.

\subsection{Transmission electron microscopy (TEM) analysis of cells}

E. coli cells were cultured overnight, diluted 25-fold and incubated in aqueous media containing $3.5 \mu \mathrm{M}$ AgNO3 for 1 hour at 37 C. Conventional lacey carbon films suspended on TEM copper grids were dampened with the bacterial suspensions, dried in air at room temperature and then studied using Jeol JEM-2100F (accelerating voltage $200 \mathrm{kV}$, point-to-point resolution $0.19 \mathrm{~nm}$ ) equipped with an energy-dispersive X-ray spectrometer (EDX) Oxford Instruments INCA. Selected area electron diffraction (SAED) patterns were obtained from areas of about 0.1-1 $\mu \mathrm{m}$ in size using corresponding selective apertures. The characteristic X-ray spectra used for elemental analysis were acquired by focusing the electron beam to a spot ranging from $1 \mathrm{~nm}$ to $1 \mu \mathrm{m}$ in diameter depending on the studied object. Note, that the prominent copper peak in the presented EDX spectra is related to the copper support of TEM specimens.

\subsection{Measurement of silver concentration}

Silver concentration was measured by graphite furnace atomic absorption spectrometry (FAAS) with electrothermal atomization and Zeeman correction of nonselective absorption on a ZeeNit P650 spectrometer (Analytik Jena, Germany) with automatic sampling duplication. Bacterial samples were homogenized in PBS, and dissolved with three volumes of pure concentrated HNO3. The silver concentration in chromatographic fractions was measured without additional processing.

Acknowledgments: This work was supported by RFBR grant 15-04-06770-a and grants \#SA6.7509.2017/8.9 and \#6.1278.2014/K of Ministry of Education and Science of Russian Federation. TEM characterizations were performed using equipment owned by the Joint Research Center "Material science and characterization in advanced technology" (Ioffe Institute, St.-Petersburg, Russia).

Author Contributions: PLV obtained resources for the study and designed it with BPN. All authors participated in analyzing the data and drafting of the article and revised it critically for important intellectual content. All authors contributed with their specific technical skills in the conduct of the study and approved the final article.

Conflicts of Interest: There are no conflicts of interest that could be perceived as prejudicing the impartiality of the research reported herein. 


\section{References}

1. Palm-Espling, M.E.; Niemiec, M.S.; Wittung-Stafshede, P. Role of metal in folding and stability of copper proteins in vitro. Biochim. Biophys. Acta 2012, 1823, 1594-1603, DOI: 10.1016/j.bbamcr.2012.01.013.

2. Tapiero, H.; Townsend, D.M.; Tew, K.D. Trace elements in human physiology and pathology. Copper; Biomed. Pharmacother. 2003, 57, 386-398, PMID: 14652164.

3. Krohn, K.A.; Link, J.M.; Mason, R.P. Molecular Imaging of Hypoxia. J. Nucl. Med. 2008, 49, 129-148, DOI: 10.2967/jnumed.107.045914.

4. $\quad$ Liang, Z.D.; Tsai, W.B.; Lee, M.Y.; Savaraj, N.; Kuo, M.T. Specificity protein $1 \mathrm{sp1}$ oscillation is involved in copper homeostasis maintenance by regulating human high-affinity copper transporter 1 expression. Mol. Pharmacol. 2012, 81, 455-464, DOI: 10.1124/mol.111.076422.

5. Arciello, M.; Longo, A.; Viscomi, C.; Capo, C.; Angeloni, A.; Rossi, L.; Balsano, C. Core domain mutant Y220C of p53 protein has a key role in copper homeostasis in case of free fatty acids overload. Biometals 2015, 28, 1017-1029, DOI: 10.1007/s10534-015-9886-0.

6. Mufti, A.R.; Burstein, E.; Duckett, C.S. XIAP: cell death regulation meets copper homeostasis. Arch. Biochem. Biophys. 2007, 463, 168-174, DOI: 10.1016/j.abb.2007.01.033.

7. Turski, M.L.; Thiele, D.J. New roles for copper metabolism in cell proliferation; signaling; and disease. J. Biol. Chem. 2009, 284, 717-721, DOI: 10.1074/jbc.R800055200.

8. Ioannoni, R.; Beaudoin, J.; Lopez-Maury, L.; Codlin, S.; Bahler, J.; Labbe, S. Cuf2 is a novel meiosis-specific regulatory factor of meiosis maturation. PLoS ONE 2012, 7, e36338, DOI: 10.1371/journal.pone.0036338.

9. Turski, M.L.; Brady, D.C.; Kim, H.J.; Kim, B.E.; Nose, Y.; Counter, C.M.; Winge, D.R.; Thiele, D.J. A novel role for copper in Ras/mitogen-activated protein kinase signaling. Mol. Cell Biol. 2012, 32, 1284-1295, DOI: 10.1128/MCB.05722-11.

10. Opazo, K.M.; Greenough, M.A; Bush, A.I. Copper: from neurotransmission to neuroproteostasis. Front. Aging Neurosci. 2014, 6, 143, DOI: 10.3389/fnagi.2014.00143.

11. Brady, C.; Crowe, M.S; Turski, M.L.; Hobbs, G.A.; Yao, X.; Chaikuad, A.; Knapp, S.; Xiao, K.; Campbell, S.L.; Thiele, D.J.; Counter, C.M. Copper is required for oncogenic BRAF signalling and tumorigenesis. Nature 2014, 509, 492-496, DOI: 10.1038/nature13180.

12. Easter, R.N.; Qilin, C.; Lai, B.; Ritman, E.L.; Caruso, J.A.; Zhenyu, Q. Vascular metallomics: copper in the vasculature. Vasc. Med. 2010, 15, 61-69, DOI: 10.1177/1358863X09346656.

13. Rubino, J.T.; Franz, K.J. Coordination chemistry of copper proteins: how nature handles a toxic cargo for essential function. J. Inorg. Biochem. 2012, 107, 129-143, DOI: 10.1016/j.jinorgbio.2011.11.024.

14. Kozlowski, H.; Kozlkowska, P.; Watly, J.; Krzywoszynska, K.; Potocki, S. General Aspects of Metal Toxicity. Curr. Med. Chem. 2014, 21, 3721-3740, PMID: 25039781.

15. Puig, S.; Lee, J.; Lau, M.; Thiele, D.J. Biochemical and genetic analyses of yeast and human high affinity copper transporters suggest a conserved mechanism for copper uptake. J. Biol. Chem. 2002, 277, 2602126030, DOI: 10.1074/jbc.M202547200.

16. Wooton-Kee, C.R.; Jain, A.K.; Wagner, M.; Grusak, M.A.; Finegold, M.J.; Lutsenko, S.; Moore, D.D. Elevated copper impairs hepatic nuclear receptor function in Wilson's disease. J. Clin. Invest. 2015, 125, 3449-3460, DOI: $10.1172 / J C I 78991$.

17. Inoue, K.; Takano, H.; Shimada, A.; Satoh, M. Metallothionein as an anti-inflammatory mediator. Mediators Inflamm. 2009, 2009, 101659, DOI: 10.1155/2009/101659.

18. Gupta, A.; Lutsenko, S. Human copper transporters: mechanism; role in human diseases and therapeutic potential. Future Med. Chem. 2009, 1, 1125-1142, DOI: 10.4155/fmc.09.84.

19. Kodama, H.; Fujisawa, C.; Bhadhprasit, W. Inherited copper transport disorders: biochemical mechanisms; diagnosis; and treatment. Curr. Drug. Metab. 2012, 13, 237-250, PMID: 21838703.

20. Mitra, J.; Guerrero, E.N.; Hegde, P.M.; Wang, H.; Boldogh, I.; Rao, K.S.; Mitra, S.; Hegde, M.L. New perspectives on oxidized genome damage and repair inhibition by pro-oxidant metals in neurological diseases. Biomolecules 2014, 4, 678-703, DOI: 10.3390/biom4030678.

21. Ouyang, P.; Gottlieb, S.H.; Culotta, V.L.; Navas-Acien, A. EDTA Chelation Therapy to Reduce Cardiovascular Events in Persons with Diabetes. Curr. Cardiol. Rep. 2015, 17, 96, DOI: 10.1007/s11886-0150656-y.

22. Denoyer, D.; Masaldan, S.; La Fontaine, S.; Cater, M.A. Targeting copper in cancer therapy: 'Copper That Cancer'. Metallomics 2015, 7, 1459-1476, DOI: 10.1039/c5mt00149h. 
23. Öhrvik, H.; Thiele, D.J. How copper traverses cellular membranes through the mammalian copper transporter 1, Ctr1. Ann. N. Y. Acad. Sci. 2014, 1314, 32-41, DOI: 10.1111/nyas.12371.

24. Parr, R.G.; Pearson, R.G. Absolute hardness: companion parameter to absolute electronegativity. J. Am. Chem. Soc. 1983, 105, 7512-7516.

25. Skvortsov, A.N.; Zatulovskiǐ, E.A.; Puchkova, L.V. Structure-functional organization of eukaryotic highaffinity copper importer CTR1 determines its ability to transport copper; silver and cisplatin. Mol. Biol. Mosk. 2012, 46, 335-347, PMID: 22670529.

26. Du, X.; Li, H.; Wang, X.; Liu, Q.; Ni, J.; Sun, H. Kinetics and thermodynamics of metal binding to the Nterminus of a human copper transporter; hCTR1. Chem. Commun. Camb. 2013, 49, 9134-9136, DOI: 10.1039/c3cc45360j.

27. Du, X.; Wang, X.; Li, H.; Sun, H. Comparison between copper and cisplatin transport mediated by human copper transporter 1 hCTR1. Metallomics 2012, 4, 679-685, DOI: 10.1039/c3cc45360j.

28. Ilyechova, E.Y.; Saveliev, A.N.; Skvortsov, A.N.; Babich, P.S.; Zatulovskaia, A.Y.; Pliss M.G.; Korzhevskii, D.E.; Tsymbalenko, N.V.; Puchkova, L.V. The effects of silver ions on copper metabolism in rats. Metallomics 2014, 6, 1970-1987, DOI: 10.1039/c4mt00107a.

29. Babich, P.S.; Skvortsov, A.N.; Rusconi, P.; Tsymbalenko, N.V.; Mutanen, M.; Puchkova, L.V.; Broggini, M. Non-hepatic tumors change the activity of genes encoding copper trafficking proteins in the liver. Cancer Biol. Ther. 2013, 14, 614-624, DOI: 10.4161/cbt.24594.

30. Kovács, D.; Szőke, K.; Igaz, N.; Spengler, G.; Molnár, J.; Tóth, T.; Madarász, D.; Rázga, Z.; Kónya, Z.; Boros, I.M.; Kiricsi, M. Silver nanoparticles modulate $\mathrm{ABC}$ transporter activity and enhance chemotherapy in multidrug resistant cancer. Nanomedicine 2016, 12, 601-610, DOI: 10.1016/j.nano.2015.10.015.

31. Sinani, D.; Adle, D.J.; Kim, H.; Lee, J. Distinct mechanisms for Ctr1-mediated copper and cisplatin transport. J. Biol. Chem. 2007, 282, 26775-26785, DOI: 10.1074/jbc.M703973200.

32. Ma, G.; Wu, Q.; Wu, X.; Arnesano, F.; Natile, G.; Sletten, E.; Liu, Y. The reaction of a platinated methionine motif of CTR1 with cysteine and histidine is dependent upon the type of precursor platinum complex. J. Inorg. Biochem. 2015, 153, 239-246, DOI: 10.1016/j.jinorgbio.2015.07.010.

33. Haas, K.L.; Putterman, A.B.; White, D.R.; Thiele, D.J.; Franz, K.J. Model peptides provide new insights into the role of histidine residues as potential ligands in human cellular copper acquisition via Ctr1. J. Am. Chem. Soc. 2011, 133, 4427-4437, DOI: 10.1021/ja108890c.

34. De Feo, C.J.; Aller, S.G.; Siluvai, G.S.; Blackburn, N.J.; Unger, V.M. Three-dimensional structure of the human copper transporter hCTR1. Proc. Natl. Acad. Sci. USA 2009, 106, 4237-4242, DOI: 10.1073/pnas.0810286106.

35. Argüello, J.M.; Raimunda, D.; Padilla-Benavide, T. Mechanisms of copper homeostasis in bacteria. Front. Cell. Infect. Microbiol. 2013, 3, 73, DOI: 10.3389/fcimb.2013.00073.

36. Jaimes-Lizcano, Y.A.; Hunn, D.D.; Papadopoulos, K.D. Filamentous Escherichia coli cells swimming in tapered microcapillaries. Res. Microbiol. 2014, 165, 166-74, DOI: 10.1016/j.resmic.2014.01.007.

37. Melo, M.M.A.; Daniele-Silva, A.; Teixeira, D.G.; Estrela, A.B.; Melo, K.R.T.; Oliveira, V.S.; Rocha, H.A.O.; Ferreira, L.S.; Pontes, D.L.; Lima, J.P.M.S.; Silva-Júnior, A.A.; Barbosa, E.G.; Carvalho, E.; FernandesPedrosa, M.F. Structure and in vitro activities of a Copper II-chelating anionic peptide from the venom of the scorpion Tityus stigmurus. Peptides 2017, 94, 91-98, DOI: 10.1016/j.peptides.2017.05.009.

38. Lichtmannegger, J.; Leitzinger, C.; Wimmer, R.; Schmitt, S.; Schulz, S.; Kabiri, Y.; Eberhagen, C.; Rieder, T.; Janik, D.; Neff, F.; Straub, B.K.; Schirmacher, P.; DiSpirito, A.A.; Bandow, N.; Baral, B.S.; Flatley, A.; Kremmer, E.; Denk, G.; Reiter, F.P.; Hohenester, S.; Eckardt-Schupp, F.; Dencher, N.A.; Adamski, J.; Sauer, V.; Niemietz, C.; Schmidt, H.H.; Merle, U.; Gotthardt, D.N.; Kroemer, G.; Weiss, K.H.; Zischka, H. Methanobactin reverses acute liver failure in a rat model of Wilson disease. J. Clin. Invest. 2016, 126, 2721 2735, DOI: 10.1172/JCI85226.

39. Hamsell, M.A.; Xue, Y.; Robinson, C.D.; Canalizo-Hernández, M.A.; Marvin, R.G.; Kelly, R.A.; Mondragón, A.; Penner-Hahn, J.E.; O'Halloran T.V. Tetrathiomolybdate inhibits copper trafficking proteins through metal cluster formation. Science 2010, 327, 331-334, DOI: 10.1126/science.1179907.

40. Juling, S.; Bachler, G.; von Götz, N.; Lichtenstein, D.; Böhmert, L.; Niedzwiecka, A.; Selve, S.; Braeuning, A.; Lampen, A. In vivo distribution of nanosilver in the rat: The role of ions and de novo-formed secondary particles. Food Chem. Toxicol. 2016, 97, 327-335, DOI: 10.1016/j.fct.2016.08.016. 
41. Zatulovskiy, E.A.; Skvortsov, A.N.; Rusconi, P.; Ilyechova, E.Y.; Babich, P.S.; Tsymbalenko, N.V.; Broggini, M.; Puchkova, L.V. Serum depletion of holo-ceruloplasmin induced by silver ions in vivo reduces uptake of cisplatin. J. Inorg. Biochem. 2012, 116, 88-96, DOI: 10.1016/j.jinorgbio.2012.07.003.

42. Sokolov, A.V.; Kostevich, V.A.; Romanico, D.N.; Zakharova, E.T.; Vasilyev, V.B. Two-stage method for purification of ceruloplasmin based on its interaction with neomycin. Biochemistry Mosc. 2012, 77, 631638, DOI: 10.1134/S0006297912060107. 